\title{
Component Importance Measures based Risk and Reliability Analysis of Vehicular Ad Hoc Networks
}

\author{
Rakhi \\ Research scholar, Electrical Engineering Department, National Institute of Technology, Kurukshetra, 136119, INDIA \\ E-mail: rakhikamra@gmail.com \\ G.L.Pahuja \\ Professor, Electrical Engineering Department, National Institute of Technology, Kurukshetra, 136119, INDIA \\ E-mail: glpahuja@nitkkr.ac.in
}

Received: 04 July 2018; Accepted: 14 August 2018; Published: 08 October 2018

\begin{abstract}
Recent year's development in communication technologies have been able to deploy a whole new range of ad hoc networks of moving vehicles namely Vehicular Ad hoc Network (VANET). The key component of Intelligent Transportation Systems (ITS) is VANET only. The Vehicular communication systems is one of the critical complex infrastructure system of any nation. Thus, reliability i.e. having a low failure probability of such critical systems is the main concern of the academia and the industry. This paper primarily focuses on the reliability modelling of VANET. The main objective of the research is to address the issue of quantifying the importance of components in contributing to the reliability and maintenance of a VANET. Reliability Block diagrams (RBD)s have been modelled for the architecture of VANET. Out of various Component Importance Measures (CIM)s available in literature, Birnbaum measure, Improvement measure and Criticality Importance measures have been used to prioritize the system components. The research work is successful in identifying the most critical and the least critical component of the Vehicular Ad Hoc Network and thus provides a solution for the design improvement, maintenance and failure diagnosis.
\end{abstract}

Index Terms - Vehicular Ad Hoc Network, Intelligent Transportation Systems, reliability, risk, Component Importance Measures, Reliability Block diagram, critical infrastructure systems, failure, maintenance, design improvement, system component prioritization.

\section{INTRODUCTION}

Today's real-world infrastructure consists of categorically complex networks such as power grid, Intelligent Transportation Systems (ITS), Internet, Wireless sensor networks etc. These highly complex networks are composed of numerous interconnected functional and structural components [3] [26].
Justifiability, reliability of these networks is a matter of prime concern for the researchers and design engineers, across the globe. The failures directly affect the operation and maintenance costs of the system [4]. In this context, the focus is to improve the reliability of the system. Vehicular Ad Hoc Network (VANET) is the vital component of the Intelligent Transportation System. Security and trustworthy communication amongst the components of VANET and further ITS is itself a challenging task [2][24][28].The applications of VANET are very diverse, not only to transfer safety, emergency messages, but also infotainment for the commuters, to make their journey a memorable experience[5]. The reliability of a system/network not only depends on its components but also on the architecture of the system/network[8][27].Since 1960s, there exists many component importance measures in literature, the thorough review of the various importance measures available in the field of reliability engineering is given by Kuo and Zhu[1][6].Component importance measures are classified on different basis such as structure[9],risk[11], reliability[12],joint importance[13]. To assess the role of components on system performance, utility component importance measure is framed by $\mathrm{Wu}$ and Chan [14]. The most common method to improve the reliability of a system is to add redundant components, this gives a need to study a redundancy important measure [7][25]. Sergio and Vaidas [15] have found a new method for evaluating importance indices using fault tree analysis. The critical infrastructure systems like ITS having VANET as an important constituent module should have the lowest probability of failure but should also possess the property of recovering after any disruptive attack or event. This property has led to the development of the resilience-based component importance measure [7]. Also, the significance of any component also depends its cost factor, well explained in [16] [23]. Ref. [17] has analyzed the reliability and survivability of VANETs using Markov Model technique and RBDs. Also Ref. [18,19] has proposed stochastic 
modelling for enhancing and exploring the reliability performance measures of the VANETs. While, all these articles have focused on evaluating reliability of VANET under different conditions and through various methods.

However, we observe that reliability enhancement through improvement in reliability hardware has been completely ignored. Thus, to address the problem of reliability improvement in complex systems/networks, the fundamental study of Component Importance Measures is very important. Decisions to identify critical components of any system are often based on one or more than one related factor. All these importance indices give an insight to the behavior of the system but there is no consensus of which measure is the best suited for a specific application.

This paper presents three suitable component importance measures Birnbaum measure, Improvement measure and Criticality Importance measure to rank the components of the Reliability Block Diagrams of the given VANET architecture. Further, the numerical results of the considered measures are analysed and discussed.

The structure of the rest of the paper is as follows: Section II presents the brief description of the VANET, its architecture, and the reliability is evaluated using their RBDs. Section III explicates the suggested importance measures for the VANET. Section IV demonstrates the numerical calculations of the chosen importance indices, results and its discussion and a brief conclusion is drawn in Section V.

\section{ARCHITECTURE AND RBDS OF VANET}

\section{A. VANET}

Application of the advanced communication technologies is realized in today's Intelligent Transport System. The most critical constituent of the modern ITS being Vehicular Ad Hoc Network [20]

The VANETs are an infrastructure - less network comprising of a cluster of mobile vehicles as nodes. Vehicles communicate with each other and with the infrastructure in a highly dynamic environment and unreliable channel conditions [21]. The modern vehicles are equipped with state of the art sensing systems, measuring devices, computing and processing equipment, thus VANETs can be termed as a cluster of smart vehicles. There are two types of nodes in VANETs: On Board Units (OBU)s and Road Side Units(RSU)s. Each vehicle act as a self-organising node and is equipped with an 'On Board Unit (OBUs)'. The component which enables vehicles to communicate with each other or with the network infrastructure is OBU. It consists of GPS (Global Positioning System), EDR (Event Data Recorder), Cameras, Antennas, Computing devices and Receivers. The network infrastructure comprises of 'Road Side Units (RSUs)' fitted along the fixed roadside structure. The role of RSUs is to act as a router between the vehicles[29].

One of the promising approaches to smart cities is through VANETs. It provides its usage in security, safety, warning messages transfer as well as comfort and infotainment. Thus, helps in traffic management and entertaining travel experience.

These applications require communication between nodes through a secured, reliable architecture. The three modes of vehicular communication are $\mathrm{V} 2 \mathrm{~V}$ (vehicle to vehicle) communication or V2I (Vehicle to Infrastructure) communication and $\mathrm{I} 2 \mathrm{~V}$ communication (Infrastructure to Vehicle. This is demonstrated in Fig.1.

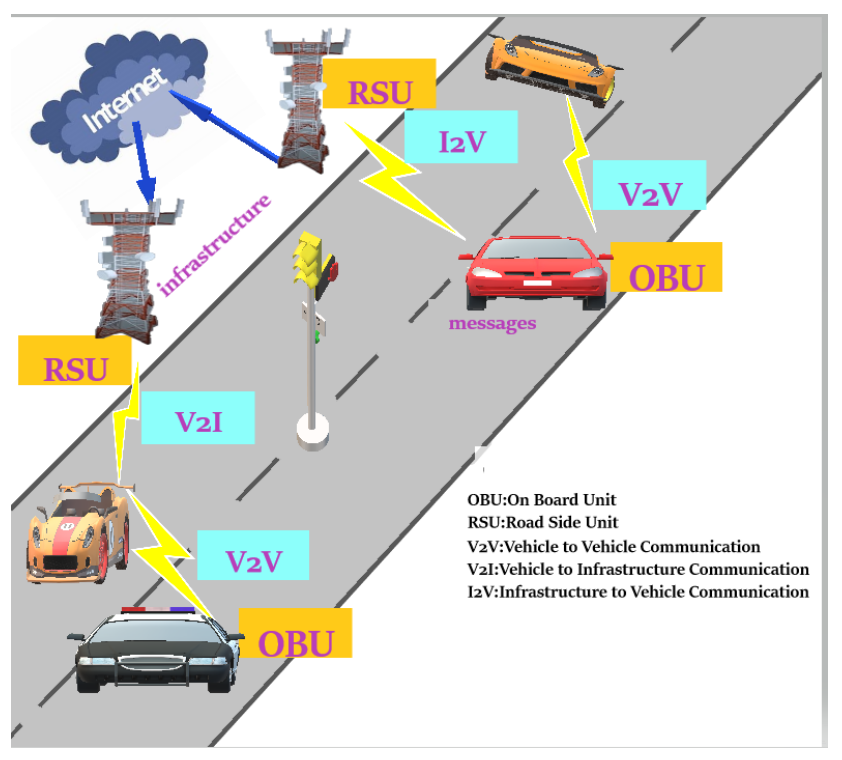

Fig.1. Architecture of VANET

In $\mathrm{V} 2 \mathrm{~V}$ communication, the message sharing can be there directly between the two vehicles within the wireless range. This is in completely open access environment, creating an ad hoc architecture.V2I communication refers to sharing of critical safety messages and warnings from vehicles to the roadside infrastructures. Such exchange of information is intended to avoid accidents on highways and to avoid areas with congestion. This supports traffic management and has environmental benefits too. In $\mathrm{I} 2 \mathrm{~V}$ communication, the network infrastructure (RSU) can broadcast alerts and warnings to the moving vehicles regarding traffic conditions, congestion points, advisory issues from the government.

VANET is reliable only if components involved in communication are reliable. Reliability $\mathrm{R}(\mathrm{t})$ is defined as the Probability of a component/system to perform its stated function under certain conditions within a specified period $(0, t)$. Reliability Block diagrams (RBDs) give the functional relationship among the components of a system. The component may be connected in series, parallel or series- parallel or complex configuration.

A RBD having series component represents that all the components must operate for the successful operation of the system. In parallel configuration, as a minimum one of the components must operate for the system to perform. The two core elements of VANET are: OBU and RSU [22]

The components in an OBU architecture are:

- Control Unit(CU): It is the brain of the OBU and 
maintains connection and coordination between the peripheral devices like EDR, Antennas, Transmitters and Receivers. Its reliability is termed as $\mathrm{R}_{\mathrm{CU}}(\mathrm{t})$ at any time ' $\mathrm{t}$ '.

- Global Positioning System(GPS): It is used to track the location of the OBUs. At any time ' $t$ ', its reliability is denoted by $\mathrm{R}_{\mathrm{GPS}}(\mathrm{t})$.

- Dedicated Short Range Communication Unit(DSRC): The primary function of this unit is to communicate between various nodes of VANET. Thereby, reliability of the DSRC unit at any time ' $t$ ', its reliability is denoted by $\mathrm{R}_{\mathrm{DSRC}}(\mathrm{t})$.

- Application Unit(AU): This module is designed for the special purpose to issue safety and warning message indicators. At any time ' $t$ ', its reliability is denoted by $\mathrm{R}_{\mathrm{AU}}(\mathrm{t})$.

- Ethernet Controller Unit (ECU): network infrastructure and further through nodes utilizes Ethernet to communicate. At any time ' $t$ ', its reliability is denoted by $\mathrm{R}_{\mathrm{EC}}(\mathrm{t})$.

- User Interface(UI): This component is fitted in the cabin, accessible to the driver to raise warning signals and instructions for various operations. This work in coherence with the Application Unit. At any time ' $\mathrm{t}$ ', its reliability is denoted by $\mathrm{R}_{\mathrm{UI}}(\mathrm{t})$.

- Power Supply Unit(PSU): The purpose of this power supply unit is to fulfil all the power requirements to the OBU, either for the connection purpose or for the processing part. At any time ' $t$ ', its reliability is denoted by $\mathrm{R}_{\mathrm{PSU}}(\mathrm{t})$.

\section{RSU (Road Side Unit)}

It has got two main components:

- Traffic Light Simulator: This component has a primary role to play in traffic management as in V2I and $\mathrm{I} 2 \mathrm{~V}$ communication, it sends the traffic signals in synchronization with the messages received from DSRC Unit. At any time ' $t$ ', its reliability is denoted by $\mathrm{R}_{\mathrm{TLS}}(\mathrm{t})$.

- Dedicated Short Range Communication Unit(DSRC):

Again, as in OBU, this unit provides a communication environment to VANET for both V2I and I2V communication. It has a very high data transfer rate with minimum latency. At any time ' $t$ ', its reliability is denoted by $\mathrm{R}_{\operatorname{DSRC}}{ }^{2}(\mathrm{t})$.

Fig.2.represents the RBD of an OBU, it is termed as $\mathrm{RBD}_{1}$ henceforth in this paper. It shows the series configuration of all the components of OBU. For a successful communication all the components must successfully operate. Fig.3. signifies the RBD of RSU, it is termed as $\mathrm{RBD}_{2}$. It is also the series arrangement of the two components, both components should operate successfully, for the successful working of the RSU.

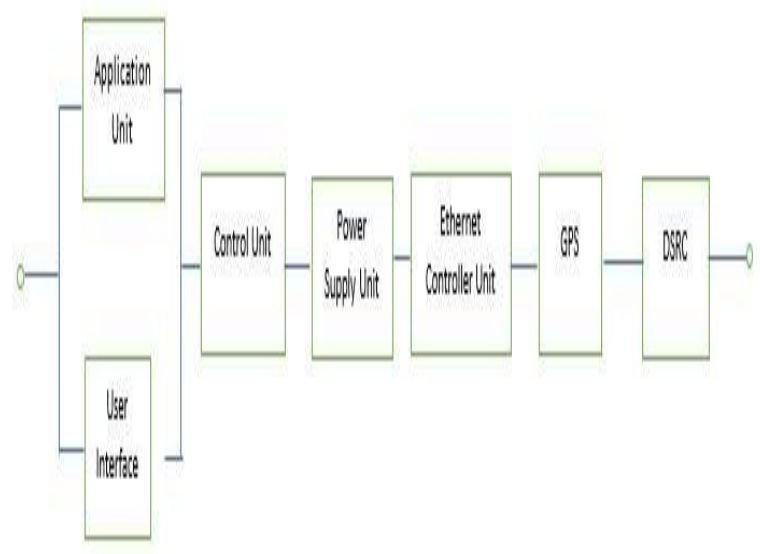

Fig.2. RBD of an On-Board Unit (OBU)

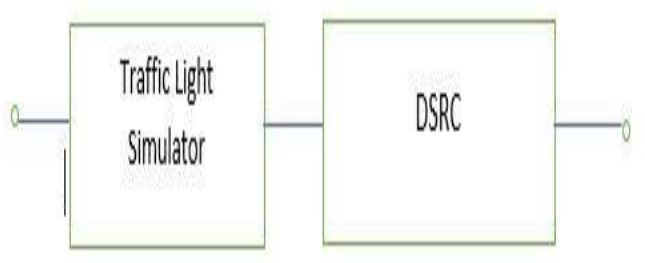

Fig.3.RBD of a Road Side Unit(RSU)

\section{COMPONENT IMPORTANCE MEASURES FOR VANET}

\section{A. Reliability Evaluation from $R B D s$}

Reliability of a system can be expressed in terms of component reliabilities.

Reliability of any component can be expressed as

$$
R(t)=e^{-\lambda t}
$$

Where $\lambda$ is failure rate and Mean Time To Failure (MTTF) is expressed as

$$
\mathrm{MTTF}=\frac{1}{\lambda}
$$

System Reliability expressed in terms of component reliabilities as from $\mathrm{RBD}_{1}$ and $\mathrm{RBD}_{2}$ respectively, is given below:

For $\mathrm{RBD}_{1}: \mathrm{R}_{\mathrm{OBU}}(\mathrm{t})=\left[1-\left(1-\mathrm{R}_{\mathrm{UI}}(\mathrm{t})\right)\left(1-\mathrm{R}_{\mathrm{AU}}(\mathrm{t})\right)\right] * \mathrm{R}_{\mathrm{CU}}(\mathrm{t}) *$

$\mathrm{R}_{\mathrm{GPS}}(\mathrm{t}) * \mathrm{R}_{\mathrm{DSRC}}(\mathrm{t}) * \mathrm{R}_{\mathrm{EC}}(\mathrm{t}) * \mathrm{R}_{\mathrm{PSU}}(\mathrm{t})$

ForRBD $2: \mathrm{R}_{\mathrm{RSU}}(\mathrm{t})=\mathrm{R}_{\mathrm{TLS}}(\mathrm{t}) * \mathrm{R}_{\mathrm{DSRC}}{ }^{2}(\mathrm{t})$

Reliability of OBU and RSU is calculated using equations 3 and 4 from the data given in Table I. 
Table 1. Reliability And Failure Rate of Components of Obu And Rsu in Vanets

\begin{tabular}{|c|c|c|}
\hline Component & $\begin{array}{c}\begin{array}{c}\text { Failure Rate } \\
\left(\mathrm{hr}^{-1)}\right.\end{array} \\
\end{array}$ & Reliability \\
\hline $\begin{array}{l}\text { Control Unit } \\
(\mathrm{CU})\end{array}$ & $1 / 880$ & 0.99886 \\
\hline $\begin{array}{l}\text { Power Supply } \\
\text { (PSU) }\end{array}$ & $1 / 850$ & 0.99882 \\
\hline $\begin{array}{l}\text { Ethernet Controller Unit } \\
\text { (ECU) }\end{array}$ & $1 / 850$ & 0.99882 \\
\hline Global Positioning System (GPS) & $1 / 870$ & 0.99885 \\
\hline $\begin{array}{c}\text { Dedicated Short Range } \\
\text { Communications } \\
\left(\mathrm{DSRC}^{1}\right)(\mathrm{OBU})\end{array}$ & $1 / 860$ & 0.99883 \\
\hline $\begin{array}{c}\text { Application Unit } \\
\text { (AU) }\end{array}$ & $1 / 850$ & 0.99882 \\
\hline $\begin{array}{l}\text { User Interface } \\
\text { (UI) }\end{array}$ & $1 / 850$ & 0.99882 \\
\hline $\begin{array}{l}\text { Traffic Light Simulator } \\
\text { (TLS) }\end{array}$ & $1 / 800$ & 0.99875 \\
\hline $\begin{array}{c}\text { Dedicated Short Range } \\
\text { Communications } \\
\left(\mathrm{DSRC}^{2}\right)(\mathrm{RSU})\end{array}$ & $1 / 820$ & 0.99878 \\
\hline
\end{tabular}

Table I shows the failure rate and reliability of components of On Board Units and Road Side Units of the VANET. Data of the failure rate has been taken from [17]. System Reliability has been calculated from the both RBDs using (3) and (4) and is evaluated as

$$
\begin{aligned}
& \mathrm{R}_{\mathrm{OBU}}(\mathrm{t})=0.994192 \\
& \mathrm{R}_{\mathrm{RSU}}(\mathrm{t})=0.997531
\end{aligned}
$$

\section{B. Component Importance Measures}

Reliability of any system depends upon reliability of its components. Each component has its worth in the system. The arrangement of the components in order of their importance is done using the knowledge of component importance measures [23]. These importance measures help in evaluating the role of each component, such that to improve the system reliability, the methods of redundancy could be applied on strong components before the weaker one. Component Importance Measures are used to quantify each module/element involvement in the system's reliability, availability, maintenance planning and risk evaluation. Various authors have studied component importance measures [8][24], Birnbaum being the first to introduce this theory with its importance measure in 1969, called the Birnbaum Importance Measure [10].

\section{Birnbaum Importance Measure}

The Birnbaum Importance Measure is used in heuristics to position the given component in a system. Birnbaum Importance Measure of a component $B I M(k)$ is stated as the partial derivative of the system reliability $\mathrm{R}_{\mathrm{s}}(\mathrm{t})$ with respect to the component reliability $\mathrm{P}_{\mathrm{k}}(\mathrm{t})$.

For any component ' $k$ ' at any time ' $t$ ' is given by

$$
B I M(k)=\frac{\partial \mathrm{Rs}(\mathrm{t})}{\partial P_{k}(t)}
$$

Also, by decomposition method,

$$
B I M(k)=R\left(1_{k}, p(t)\right)-R\left(0_{k}, p(t)\right)
$$

Where

$R\left(1_{k}, p(t)\right)$ : system reliability when $\mathrm{k}^{\text {th }}$ component is working.

$R\left(0_{k}, p(t)\right)$ : system reliability when $\mathrm{k}^{\text {th }}$ component is failed.

That is, $\operatorname{BIM}(\mathrm{k})$ gives the rate of rise in system reliability with respect to rise in component reliability. It depends upon the arrangements of the components or the basic events in the system.

\section{Improvement Potential Importance Measure}

Improvement Potential Importance Measure, IPM(k) of the $\mathrm{k}^{\text {th }}$ component of any system is the increase in system reliability when component ' $\mathrm{k}$ ' is perfect ( when its reliability is $100 \%$ i.e $\left.\mathrm{p}_{\mathrm{k}}(\mathrm{t})=1\right)$ [ ].In other words, it denotes the maximum potential of a system to improve its reliability that can be obtained by improving the reliability of component ' $\mathrm{k}$ '.

That is,

$$
\operatorname{IPM}(k)=R\left(1_{k}, p(t)\right)-R(p(t))
$$

It is the difference between system reliability with perfect component ' $\mathrm{k}$ ' and the system reliability with actual component ' $\mathrm{k}$ '.

\section{E. Criticality Importance Measure}

The Criticality Importance Measure, CIR(k) of component ' $k$ ' at any time ' $t$ ' is the probability that component $\mathrm{k}$ is critical for the system and is failed at any time ' $\mathrm{t}$ '.

When it is known that the system has failed at any time ' $\mathrm{t}$ ', $\mathrm{CIR}(\mathrm{k})$ is defined as:

$$
\begin{gathered}
C I R(k)=\left[R\left(1_{k}, p(t)\right)-R\left(0_{k}, p(t)\right)\right]\left\{\frac{1-P_{k}(t)}{1-\mathrm{Rs}(\mathrm{t})}\right\} \\
C I R(k)=\left[(B I M(k)]\left\{\frac{1-P_{k}(t)}{1-\mathrm{Rs}(\mathrm{t})}\right\}\right.
\end{gathered}
$$

\section{COMPONENT IMPORTANCE MEASURES FOR VANET}

The components of the On Board Units and Road Side Units of the VANET are prioritized and ranked by means of the three importance measures namely Birnbaum Importance Measure, Improvement Potential Measure, Criticality Importance Measure. The results are depicted in Table II for OBU and Table III for RSU. 
Table 2. Component Importance Measures for Obu in VANETS

\begin{tabular}{|l|c|c|c|}
\hline Component & BIM & IPM & CIM \\
\hline Control Unit (CU) & 0.995326 & $1.13 \times 10^{-3}$ & 0.195368 \\
\hline Power Supply (PSU) & 0.995366 & $1.17 \times 10^{-3}$ & 0.2022318 \\
\hline $\begin{array}{l}\text { Ethernet Controller } \\
\text { Unit (ECU) }\end{array}$ & 0.995366 & $1.17 \times 10^{-3}$ & 0.2022318 \\
\hline $\begin{array}{l}\text { Global Positioning } \\
\text { System (GPS) }\end{array}$ & 0.995336 & $1.14 \times 10^{-3}$ & 0.1970844 \\
\hline $\begin{array}{l}\text { Dedicated Short Range } \\
\text { Communications } \\
\text { (DSRC }{ }^{1} \text { (OBU) }\end{array}$ & 0.994192 & $8.22 \times 10^{-7}$ & 0.200281 \\
\hline \begin{tabular}{l} 
Application Unit (AU) \\
\hline User Interface (UI)
\end{tabular} & $1.17 \times 10^{-4}$ & $1.38 \times 10^{-6}$ & $2.38 \times 10^{-4}$ \\
\hline
\end{tabular}

Table 3. Component Importance Measures for RSU in VANETS

\begin{tabular}{|l|c|c|c|}
\hline Component & BIM & IPM & CIM \\
\hline $\begin{array}{l}\text { Traffic Light Simulator } \\
\text { (TLS) }\end{array}$ & 0.9988 & $1.247 \times 10^{-4}$ & 0.50586 \\
\hline $\begin{array}{l}\text { Dedicated Short Range } \\
\begin{array}{l}\text { Communications (DSRC } \\
\text { (RSU) }\end{array}\end{array}$ & 0.9987 & $1.217 \times 10^{-4}$ & 0.4935185 \\
\hline
\end{tabular}

The three importance measures for the various components of the reliability block diagrams of VANET architecture are calculated and tabulated in Table III and Table IV. The numerical results give the following rankings with respect to each importance measure which is depicted in the graphical representation in following figures

In fig. 4, For BIM:

$\mathrm{PSU}, \mathrm{ECU}>\mathrm{GPS}>\mathrm{CU}>\mathrm{DSRC}>\mathrm{AU}, \mathrm{UI}$

and in fig.5: TLS $>$ DSRC

In fig. 6, For IPM

PSU, ECU $>$ GPS $>$ CU $>$ AU, UI $>$ DSRC

and In fig. 7, DSRC > TLS

In fig. 8,For CIM:

PSU, ECU $>$ DSRC $>$ GPS $>$ CU $>$ AU, UI

and in fig.9. TLS $>$ DSRC

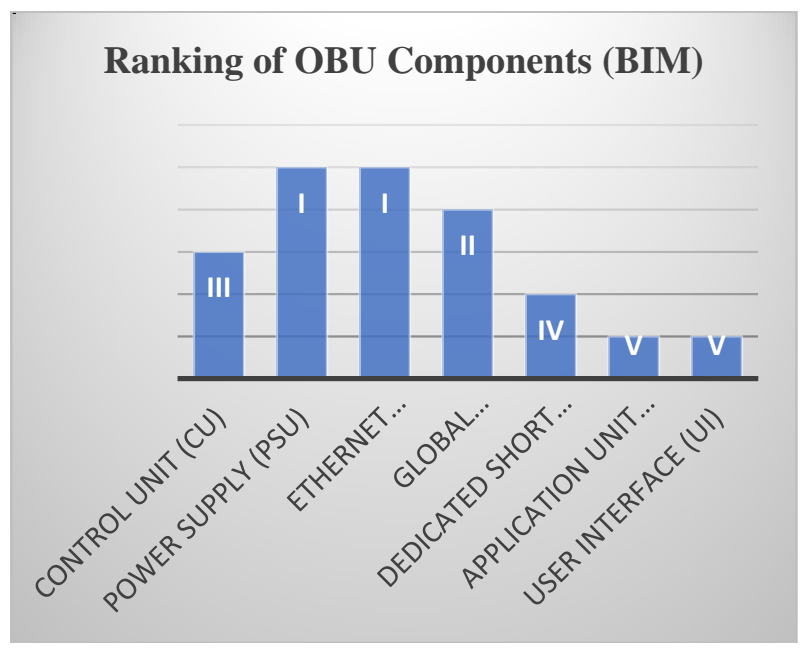

Fig.4. Graph Representing Ranking of OBU Components using BirnBaum Importance Measure (BIM)

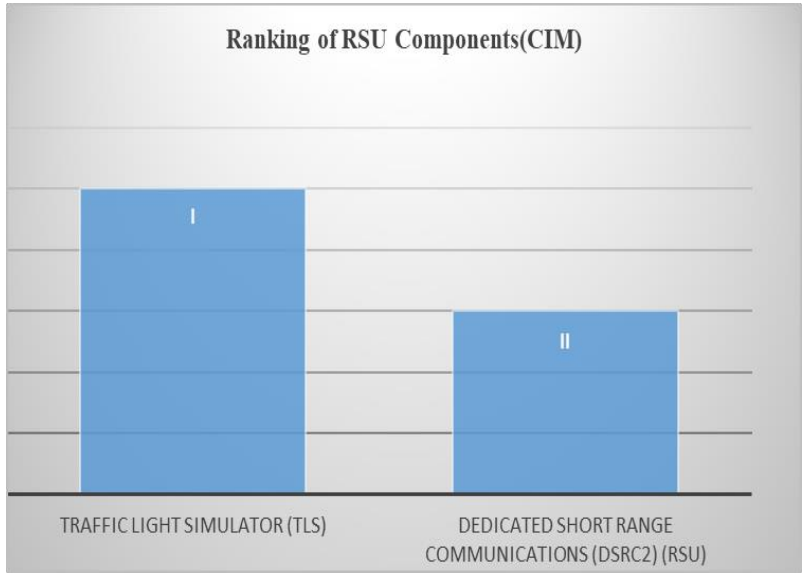

Fig.5. Graph Representing Ranking of RSU Components using BirnBaum Importance Measure (BIM)

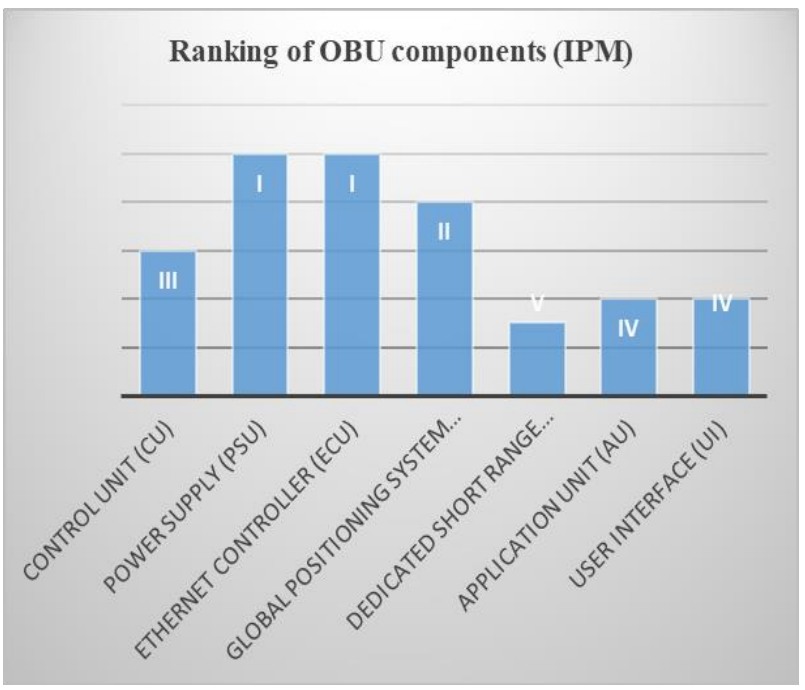

Fig.6. Graph Representing Ranking of OBU Components using Improvement Potential Measure (IPM)

\section{Ranking of RSU Components(IPM)}

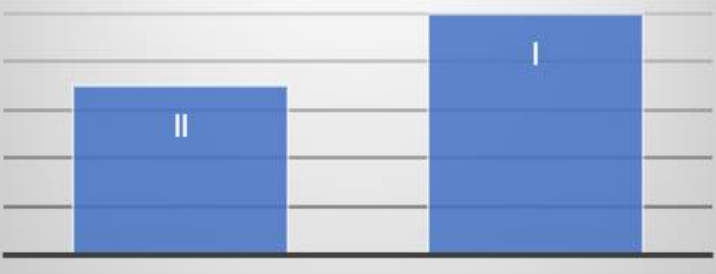

TRAFFIC LIGHTSIMULATOR DEDICATED SHORTRANGE

(TLS) COMMUNICATIONS (DSRC2)

(RSU)

Fig.7. Graph Representing Ranking of RSU Components using Improvement Potential Measure (IPM) 


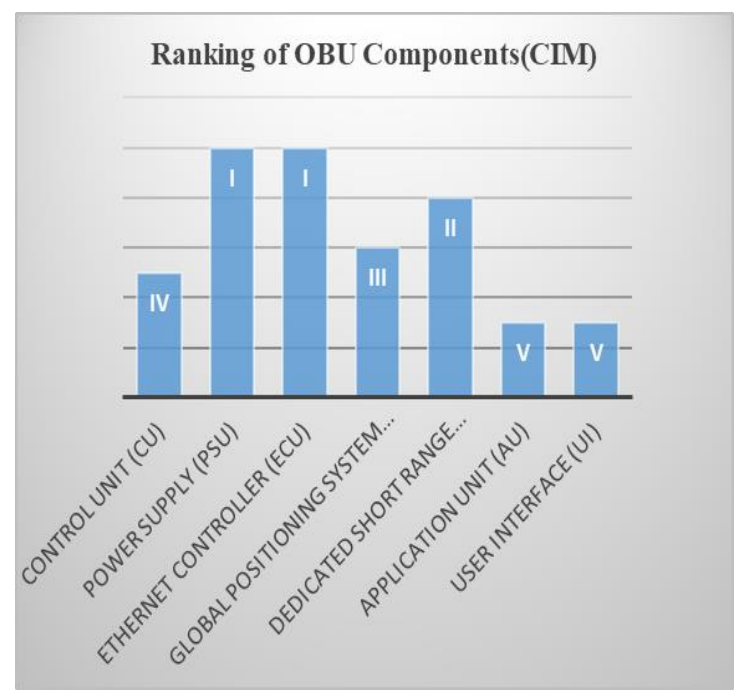

Fig.8. Graph Representing Ranking of OBU Components using Criticality Importance Measure (CIM)

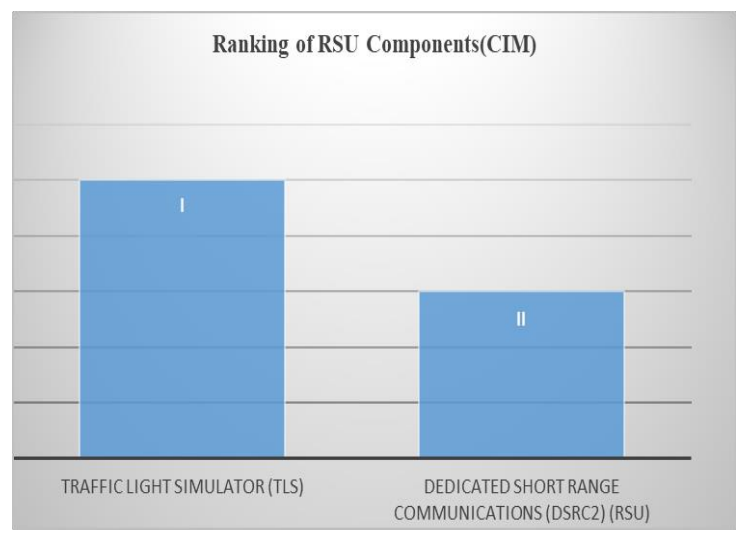

Fig.9. Graph Representing Ranking of RSU Components using Criticality Importance Measure (CIM)

The above observations show that the three chosen importance measures do not give the same results, i.e. ranking order of the components are not matching.

But all these results, show one thing in common that the Power Supply unit(PSU) and Ethernet Controller Unit (ECU) are the most critical component in the VANET architecture. It is understandable, breakdown of the power supply unit causes the failure of all the components further. This indicates that to improve the reliability of the VANET system, first redundancy should be provided to the power supply unit. Or, there should be an alternative source of power available to OBU. Also, another equally significant component is ECU, as failure of ECU would lead to network failure and loss of information exchange from downstream and RSU too. The next critical component as given by BIM and IPM is the GPS but CIM has positioned it after DSRC on the third place. For VANETs, which are highly mobile dynamic network with moving vehicles, itself acting as nodes, GPS is the most important component. The real time information about the movement of the vehicle is available through GPS only. So, it is justified that Birnbaum and Improvement Potential measures give realistic ranking in comparison with CIM. Again, the main Control Unit(CU) holds the next rank after the GPS unit. The Control unit ranks high than User Interface (UI) and Application Unit (AU), clearly because control unit is the brain behind all other parts in OBU. It controls or give directions to other components in the system to perform for an application. BIM rightly gives DSRC unit a higher rank than AU, UI and TLS in RSU model.

As DSRC is responsible for appropriate communication and exchanging information with help of ECU and GP to the other OBU or RSU. The Application Unit(AU) and User Interface (UI) operated by the driver of the vehicle to raise the warnings and alerts, are connected in parallel, so have the same rank and are of the least critical component in the VANET architecture.

In RSU model, the two important measures BIM and CIM suggest TLS (Traffic Light Simulator) as more critical important than DSRC.

\section{CONCLUSIONS}

Reliability analysis is a critical study in any system's design and then its maintenance. Cost of maintenance and operation can be reduced by improving the reliability of the system. Precisely, the main task is to prioritize the components based on their importance for a successful, reliable performance of any system. This research work has been able to address the issue of quantifying the importance of components in contributing to the reliability and maintenance of a VANET. In this paper, reliability importance measures for architecture of VANET are calculated and analysed. Ranking of components of VANET give an insight to its most critical components. PSU and ECU being the most critical component of the OBU in VANET architecture. Knowledge of the criticality of these components can help in increasing the performance of the system optimally. The three importance measures namely Birnbaum, Improvement Potential and Criticality Importance have given their justified rankings of the various components of VANET architecture.

\section{REFERENCES}

[1] W. Kuo and X. Zhu, "Some Recent Advances on Importance Measures in Reliability," in IEEE Transactions on Reliability, vol. 61, no. 2, pp. 344-360, June 2012.

[2] Kumar, N. and Chilamkurti, N., "Collaborative trust aware intelligent intrusion detection in VANETs." Computers \& Electrical Engineering, vol. 40, no.6, pp.1981-1996,2014.

[3] Whitman, M.G., Barker, K., Johansson, J. and Darayi, M., "Component importance for multi-commodity networks: Application in the Swedish railway" Computers \& Industrial Engineering, vol.112, pp.274-288,2017

[4] Fang, S. and Wakabayashi, H., "Cost-benefit analysis for traffic network reliability improvement." Procedia-Social and Behavioral Sciences, vol.54, pp.696-705, 2012.

[5] Rathore, M.M., Paul, A., Ahmad, A., Chilamkurthi, N., Hong, W.H. and Seo, H., "Real-time secure communication for Smart City in high-speed Big Data environment" Future Generation Computer Systems, vol.83, pp.638-652,2018. 
[6] Kuo, W. and Zhu, X., "Relations and generalizations of importance measures in reliability." IEEE Transactions on Reliability, vol.61, no.3, pp.659-674, 2012.

[7] Barker, K., Ramirez-Marquez, J.E. and Rocco, C.M., "Resilience-based network component importance measures." Reliability Engineering \& System Safety, vol.117, pp.89-97, 2013.

[8] W. Kuo and X. Zhu, Importance measures in reliability, risk, and optimization: principles and applications. John Wiley \& Sons, 2012.

[9] Ramirez-Marquez, Jose Emmanuel, and David W. Coit. "Composite importance measures for multi-state systems with multi-state components." IEEE Transactions on Reliability vol.54,no.3,pp.517-529,2005

[10] Z. W. Birnbaum, "On the importance of different components in a multicomponent system," in Multivariate Analysis II, P. R. Krishnaian Ed. New York, NY, USA: Academic, 1969, pp. 581-592.

[11] Aven, T. and Nøkland, T.E., "On the use of uncertainty importance measures in reliability and risk analysis" Reliability Engineering \& System Safety, vol.95,no.2, pp.127-133,2010.

[12] Wang, Wendai, James Loman, and Pantelis Vassiliou. "Reliability importance of components in a complex system." Reliability and Maintainability, 2004 Annual Symposium-RAMS. IEEE, 2004.

[13] Gao, Xueli, Lirong Cui, and Jinlin Li. "Analysis for joint importance of components in a coherent system." European Journal of Operational Research vol.182, no. 1, pp.282-299, 2007.

[14] S. Wu, L. Chan, "Performance utility-analysis of multistate systems", IEEE Transactions on Reliability, vol. 52, no. 1, pp. 14-21, 2003.

[15] Contini, S. and Matuzas, V., " New methods to determine the importance measures of initiating and enabling events in fault tree analysis", Reliability Engineering \& System Safety, vol.96,no.7, pp.775-784,2011.

[16] Dui, Hongyan, Shubin Si, and Richard CM Yam. "A costbased integrated importance measure of system components for preventive maintenance", Reliability Engineering \& System Safety vol.168, pp.98-104, 2017.

[17] Dharmaraja, S., Vinayak, R. and Trivedi, K.S., "Reliability and survivability of vehicular ad hoc networks: An analytical approach", Reliability Engineering \& System Safety, vol.153, pp.28-38, 2016.

[18] X. Ma, X. Yin, K. Trivedi, "On the reliability of safety applications in VANETs", Int. J. Perform. Eng., vol. 8, no. 2, pp. 115-130, May 2012.

[19] X. Ma, X. Yin, M. Wilson, K. Trivedi, "MAC and application-level broadcast reliability in VANETs with channel fading", Proc. ICNC, pp. 756-761, Jan. 2013.

[20] N. Kumar, S. Misra, M. S. Obaidat, "Collaborative learning automata-based routing for rescue operations in dense urban regions using vehicular sensor networks", IEEE Systems Journal, vol. 9, no. 3, pp. 1081-1090, Sep. 2015.

[21] N. Kumar, N. Chilamkurti, J. P. C. Rodrigues, "Learning automata-based opportunistic data aggregation and forwarding scheme for alert generation in vehicular ad hoc networks", Computer Communications, vol. 39, no. 2, pp. 22-32, Feb. 2014.

[22] S. Dharmaraja, R. Vinayak, Xiaomin Ma and K. S. Trivedi, "Reliability and survivability of vehicular ad hoc networks", 2012 International Symposium on Performance Evaluation of Computer \&
Telecommunication Systems (SPECTS), Genoa, , pp. 17,2012

[23] R.K. Rao Alla, Pahuja G.L, Lather J.S, "Risk Based Ranking Using Component Cost Importance Measure", International Journal of Engineering and Manufacturing, vol.5, no.1, pp. 26-32, 2015.

[24] Rakhi and Pahuja, G.L. "A Reliable Solution to Load Balancing with Trust Based Authentication Enhanced by Virtual Machines", International Journal of Information Technology and Computer Science, vol.9,pp. 64-71,2017.

[25] Tarun Kumar Sharma, Millie Pant, "Redundancy Level Optimization in Modular Software System Models using ABC", International Journal of Intelligent Systems and Applications(IJISA), vol.6, no.4, pp.40-48, 2014.

[26] Shah, Vidhi R., Sejal V. Maru, and Rutvij H. Jhaveri. “An Obstacle Detection Scheme for Vehicles in an Intelligent Transportation System", International Journal of Computer Network and Information Security, vol.10, pp.23-28, 2016.

[27] H. Hajian-Hoseinabadi, "Reliability and component importance analysis of substation automation systems," International Journal of Electrical Power Energy Systems, vol. 49, pp 455-463, 2013.

[28] Akash Vaibhav, Dilendra Shukla, Sanjoy Das, Subrata Sahana, Prashant Johri, "Security Challenges, Authentication, Application and Trust Models for Vehicular Ad Hoc Network- A Survey", International Journal of Wireless and Microwave Technologies(IJWMT), vol.7, no.3, pp.36-48, 2017.

[29] Ramneek Kaur, "RSUs Deployment Using Parallel Scheduling" International Journal of Computer Network and Information Security, vol. 5, pp.42-49, 2015.

\section{Authors' Profiles}

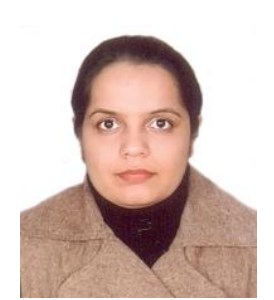

Rakhi, A dynamic research scholar who has a passion to learn. She is pursuing Ph.D. in Electrical Engineering from National Institute of Technology, Kurukshetra Haryana. She has done M.Tech in Power Engineering from Punjab Technical University, Jalandhar, Punjab. She is an active researcher and her areas of interests are Reliability Engineering, Fault Tolerant Systems, and Improvement of Quality of Service (QoS) parameters of communication networks. She has published more than 5 national and 3 international papers.

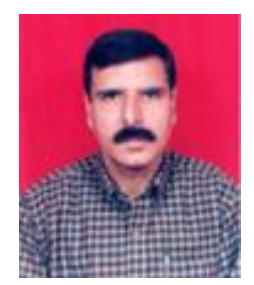

Prof. G.L.Pahuja did his B.Sc. (Electrical Engineering), M. Tech (Control System), and $\mathrm{PhD}$ in the area of Reliability Engineering from REC Kurukshetra affiliated to Kurukshetra University, Kurukshetra, Haryana, India. $\mathrm{He}$ is currently working as a Professor in the Department of Electrical Engineering, National Institute of Technology, Kurukshetra. He has 32 years of teaching experience.

His research interests include System and Reliability Engineering, Fault tolerant systems, Reliability evaluation and optimization of communication networks. 
How to cite this paper: Rakhi, G.L.Pahuja,"Component Importance Measures based Risk and Reliability Analysis of Vehicular Ad Hoc Networks", International Journal of Computer Network and Information Security(IJCNIS), Vol.10, No.10, pp.38-45, 2018.DOI: 10.5815/ijcnis.2018.10.05 